\title{
New approaches to pediatric dilated cardiomyopathy in current practice
}

\author{
Amalia Fagarasan, Maria Oana Sasaran \\ Department of Pediatrics III, "George Emil Palade" University of Medicine, Pharmacy, Sciences and \\ Technology of Targu Mures, Romania
}

\begin{abstract}
Progresses to radiologic and molecular genetics fields created the premisses for the development of a new, descriptive classification system of cardiomyopathies, known under the MOGE (S) acronym, with the help of informations provided by molecular genetic testing that led to better knowledge regarding their physiopathogenic backgrounds, the implementation of a descriptive, nosologic phenotype-genotype and the establishment of an accurate clinic and genetic diagnosis. Dilated cardiomyopathy (DCM) in children remains the most frequent type of cardiomyopathy, representing an important cause of death in the first 2 years of life, and its impact at neonatal age is not fully understood, due to the low number of studies regarding its real incidence. Its death rate is high, $10 \%$ of neonatal deaths of cardiac origin being caused by DCM. Ecocardiography helps in establishing the diagnosis and evolution and therapy monitoring. Modern ultrasound techniques (tissue Doppler or speckle tracking), as well as 3D ultrasound provide highly accurate data. Paraclinic assessments, such as neuropeptides (BNP, NT-proBNP), have both diagnostic and prognostic roles. Medical treatment recommended for congestive cardiac failure symptom relief consists of angiotensine converting enzyme inhibitors (the long acting ones are preffered - Lisinopril), mineralocorticoid receptors antagonists and beta-blockers (Bisoprolol), which act by decreasing the afterload, limiting the ventricular remodelation process and can easily be administered, in unique dose. Novel therapeutic approaches have aroused, such as regenerative therapy of cardiomyocytes. Cardiac transplant remains a therapeutic option limited by a small number of donors.

Conclusions. Diagnostic and therapeutic approach of DCM have been substantially improved, integration in current practice of new diagnostic methods and regenerative therapeutic approaches can change the prognostic perspective of this disease.
\end{abstract}

Keywords: dilated cardiomyopathy, children, cardiac regenerative therapy

\section{INTRODUCTION}

The importance of myocardic pathology as a cause of pediatric death of cardiac origin cannot be forseen. Cardiomyopathies are defined as anomalies with initial structural and functional involvement of the myocardium, after excluding conditions which evolve to severe myocardial dysfunction in the absence of proper treatment (serious cardiac congenital anomalies, arterial hypertension) (1).

A subject of great interest is the classification of cardiomyopathies, the one performed on specific morfo-functional cryteria classifying it into primary types with familial (genetic) and non-familial (nongenetic) subtypes (2). Progresses in the molecular genetic field allowed the opening towards new perspectives regarding etiopathogenics, diagnosis and treatment. Starting with 2013 a new, much more elaborated classification system has been implemented, known under the MOGE (S) aconym, a descriptive system in which informations provided by molecular genetic testings created the premises towards a better knowledge of physiopathogical basis, implementation of a descriptive nosologic phenotype-genotype and establisment of an accurate clinic and genetic diagnosis $(3,4)$. A detailed, descriptive diagnosis is concluded for each patient, depending on their specific clinic and genetic characteristics (phenotype/genotype) and the management of cardiomyopathies becomes personalised (target of future medicine) (5). Genotypes drive the diagnosis and therapeutic decisions and can in equal matter help conduct a correct screening for first degree relatives (genetic, predictive ,waterfall” 
test establishes a prediction index and enhances the development of a follow-up strategy regarding letal arrhythmia risk in case of „malignant” mutations or sudden death risk, as well as prediction of disease transmission to the succesors) (6).

\section{EPIDEMIOLOGY AND PATHOPHYSIOLOGY}

Dilated cardiomyopathy (DCM) in children remains by far the most frequent type, comprising more than $50 \%$ of the total number of cardiomyopathies and is one of the most frequent causes of congestive cardiac failure (CCF), being responsible for a high death rate in the first two years of life $(7,8)$. Its unanymous accepted definition is based upon cardiac ultrasound cryteria: dilation and alteration of the systolic function of the left ventricle, ultrasonographically cuantified through an ejection fraction $(\mathrm{EF})<40 \%$ and a teledyastolic dimension with a $\mathrm{Z}$ score $>2$ (9). A pecullarity of pediatric patholoy is represented by the epidemiologic features of cardiomyopathies in newborns, difficult to define due to the low number of studies, with an estimated incidence of around 1: 10.000 live births, but responsible for approximately $10 \%$ of neonatal deaths of cardiac origin $(9,10)$. Inflammatory diseases of the myocardium, regardless of age, are one of the main causes of DCM (11). Relationship between myocarditis and DCM is uncertain, but a high number of studies and experiments conducted on animals explains the three stage evolvement from the initial episode (viral infection) to the constitution of cardiomyopathy (12):

- Initial stage is characterised by an initial myocardial insult (viral infection in most of the cases), which is silent from a clinical point of view and difficult to diagnose; most frequent viral infections associated with DCM are caused by Coxsackie type B and Adenoviruses (13).

- Stage two, in which triggering of autoimmune mechanisms leads to a progressive myocardial deterioration, with first clinical manifestations of CCF and diagnosis of the disease (14).

- Stage three, in which DCM is already installed, with typical symptoms (14).

Diagnostic and therapeutic implications of each of these phases are certainly pretty different. CDM pathogenics is believed to result from an association between myocyte disfunction mediated directly by the virus and immune response (tissular mediated lesion). For a correct diagnosis identification of viral genoma inside myocardial tissue with the help of polymerase chain reaction (PCR) is crucial, but difficult to achieve in daily practice $(15,16)$.

\section{DIAGNOSTIC TOOLS - IMPORTANCE OF ECHOCARDIOGRAPHY}

Sugestive clinical tableau at low ages is the one of CCF: feeding difficulties, excessive sweating, tachypnea, tachycardia, cold extremities and weak pulse (signs of decreased cardiac output). Following signs and symptoms can appear in older ages: dyspnea during effort and at rest, pale-cyanotic extremities, hepatomegaly \pm pain in the right hypochondrium, anorexia, peripheral edema and anasarca, in advanced stages (ascytes, pericarditis, pleuresia) (17).

M, 2D and Doppler ultrasound facilitates diagnosis and follow-up of therapy efficacy on ventriular function. Cardiac ultrasound brings in a series of supplimentary data, as it allows the assessment of: sphericity index (ratio between longitudinal/transverse diameter of left ventricle), with values $<1,5$ representing an indicator of abnormal remodelation, the end-diastolic and end-systolic volumes of the left ventricle, depending on the body surface (increased values), right ventricle function, mitral and tricuspid valve regurgitation, as well as $\mathrm{dp} / \mathrm{dt}$ ratio, lower values than 600 being indicatory of severe sytolic dysfunction of the left ventricle. Intracavitary thrombi or spontaneous echo contrast appear due to severe ventricular dysfunction. Today, we benefit from advanced technologies and modern evaluation methods: tissue Doppler echocardiography or speckle tracking which allow calculation of global and segmental function of the left ventricle. High precision meassurements of left ventricular and atrial volumes, as well as assessment of right ventricular function can be performed using 3D ultrasound $(18,19)$.

Paraclinical examinations, such as neuropeptides (brain natriuretic peptide - BNP, N-terminal pro-brain natriuretic peptide - NT-proBNP), with levels which are bigger than normal, are recommended as cuantification methods with high diagnostic and prognostic value $(20,21)$.

The following will be supervised: renal, hepatic, endocrine function (for possible thyroid dysfunctions) (22). Autoimmune processes will be investigated (23). Proteinuria, in combination with hyponatremia and increased urinary density are suggestive of cardiac decompensation (22).

\section{TREATMENT - FROM CLASSICAL APPROACH TO NOVEL REGENERATIVE AND BRIDGING THERAPY}

Treatment of CCF using angiotensin converting enzyme inhibitors (preferably long-acting), angiotensin receptor blockers (Spironolactone) and beta- 
blockers is considered the best option, as these drugs act by decreasing cardiac output and limiting ventricular remmodelation process (24). In the situation of chronic, decompensated CCF, which no longer responds to chronic oral medication, initiation of intravenous, inothropic therapy is recommended, which includes Levosimendan, phosphodiesterase inhibitors-Milrinone, Dobutamine, Dopamine, as well as parenteral diuretics (Furosemide) (25). New therapeutic methods, recommended according to the experience of the Giessen centre, from Germany, include pulmonary artery banding for functional regeneration in children with DCM, younger than 6 years (with better results in those younger than 3 years). This procedure could improve the prognosis of the disease and is recommended especially in cases awaiting a cardiac transplant, with cardiac failure NYHA/Ross III or IV, with severe impairment of left ventricular function $(\mathrm{EF}<30 \%)$, who have not exhibited a good response to inotropic, intravenous treatment given in maximal doses and chronic optimal medical treatment, and who do not have any other type of structural cardiac abnormalities, including a normal right ventricle function (preferably cuantified by an MRI) (26). Heart transplant remains a limited therapeutic option (low number of donors compared to the very high demand) and is reserved to children who have not responded to inotropic parenteral treatment given in maximal doses nor to optimal chronic medical treatment (7). Other treatment options which have rosen survival rate in

\section{REFERENCES}

1. Report of the WHO/ISFC task force on the definition and classification of cardiomyopathies. Br Heart J. 1980 Dec;44(6):672-3.

2. Elliott P, Andersson B, Arbustini E, Bilinska Z, Cecchi F, Charron P et al. Classification of the cardiomyopathies: A position statement from the European Society Of Cardiology Working Group on Myocardial and Pericardial Diseases. Eur Heart J. 2008 Jan;29(2):270-6.

3. Arbustini E, Narula N, Tavazzi L, Serio A, Grasso M, Favalli V et al. The MOGE(S) classification of cardiomyopathy for clinicians. J Am Coll Cardiol. 2014 Jul 22;64(3):304-18.

4. Dec GW, Arbustini E. Utilizing the MOGE(S) Classification for Predicting Prognosis in Dilated Cardiomyopathy. J Am Coll Cardiol. 2015 Sep 22;66(12):1324-6.

5. Hazebroek MR, Moors S, Dennert R, van den Wijngaard A, Krapels I, Hoos M et al. Prognostic Relevance of Gene-Environment Interactions in Patients With Dilated Cardiomyopathy: Applying the MOGE(S) Classification. J Am Coll Cardiol. 2015 Sep 22;66(12):1313-23.

6. Şahan E, Şahan S, Karamanlıoğlu M, Gul M, Tufekcioğlu O. The MOGE(S) classification : A TNM-like classification for cardiomyopathies. Herz. 2016 Sep;41(6):503-6.

7. Caviedes Bottner P, Córdova Fernández T, Larraín Valenzuela M, Cruces Romero Presentación de Casos Clínicos P. Dilated cardiomyopathy and severe heart failure. An update for pediatricians. Arch Argent Pediatr. 2018 01;116(3):e421-8.

8. Towbin JA, Lowe AM, Colan SD, Sleeper LA, Orav EJ, Clunie S et al. Incidence, causes, and outcomes of dilated cardiomyopathy in children. JAMA. 2006 Oct 18;296(15):1867-76. severe cases are extracorporeal membrane oxigenation - ECMO and ventricular assist device (produced by Berlin Heart) -, which are devices available for bridging to heart transplantation $(27,28)$. Treatment methods available in adult populations, such as biventricular cardiac resynchronization therapy and cardioverter implanting for ventricular arrhytmias with potentially malignant outcome can also be used in children, but experience is limited on this matter (29).

\section{EVOLUTION AND PROGNOSIS}

Evolution of DCM varies, depending on its ethiology (7).

Prognosis is influenced by factors which negatively impact the progression of the disease: symptoms coresponding to NYHA/Ross class III or IV, presence of endomyocardial fibroelastosis, progressive mitral valve insufficiency, right ventricular dilation and dysfunction, arrythmias or conduction disorders and $\mathrm{EF}$ lower than $30 \%$ (30).

\section{CONCLUSIONS}

Therapeutic and diagnostic approach of DCM underwent substantial improvements, whereas integration into daily practice of new diagnosis methods and regenerative treatment options can change the prognostic perspective of the disease.

Conflict of interest: none declared Financial support: none declared

9. Lipshultz SE, Law YM, Asante-Korang A, Austin ED, Dipchand Al, Everitt MD et al. Cardiomyopathy in Children: Classification and Diagnosis: A Scientific Statement From the American Heart Association. Circulation. 2019 Jul 2;140(1):e9-68.

10. Lipshultz SE, Sleeper LA, Towbin JA, Lowe AM, Orav EJ, Cox GF et al. The incidence of pediatric cardiomyopathy in two regions of the United States. N Engl J Med. 2003 Apr 24;348(17):1647-55.

11. Schultheiss H-P, Fairweather D, Caforio ALP, Escher F, Hershberger $\mathrm{RE}$, Lipshultz SE et al. Dilated cardiomyopathy. Nat Rev Dis Primers. 2019 09;5(1):32.

12. Wexler RK, Elton T, Pleister A, Feldman D. Cardiomyopathy: An Overview. AFP. 2009 May 1;79(9):778-84.

13. Huber SA. Viral Myocarditis and Dilated Cardiomyopathy: Etiology and Pathogenesis. Curr Pharm Des. 2016;22(4):408-26.

14. Mason JW. Myocarditis and dilated cardiomyopathy - An inflammatory link. Cardiovasc Res. 2003 Oct 15;60(1):5-10.

15. Schild DP, Ricciardi SI, Hellige JG, Vogel R, Arenja N. Current Pathophysiological and Genetic Aspects of Dilated Cardiomyopathy. Visions of Cardiomyocyte - Fundamental Concepts of Heart Life and Disease [Internet]. 2019 Jan 24 [cited 2020 Mar 1]; Available from: https://www.intechopen.com/books/visions-of-cardiomyocytefundamental-concepts-of-heart-life-and-disease/currentpathophysiological-and-genetic-aspects-of-dilated-cardiomyopathy

16. Rose NR. Viral myocarditis. Curr Opin Rheumatol. 2016 Jul; 28(4):383-9. 
17. Luk A, Ahn E, Soor GS, Butany J. Dilated cardiomyopathy: A review. J Clin Pathol. 2009 Mar;62(3):219-25.

18. Zairi I, Mzoughi K, Jabeur M, Jnifene Z, Ben Moussa F, Kamoun S, et al. Right ventricular systolic echocardiographic parameters in dilated cardiomyopathy and prognosis. Tunis Med. 2017 Feb;95(2):87-91.

19. Rivero Jiménez N, Deiros Bronte L, Castaño Andreu E, GutiérrezLarraya Aguado F. [2D strain in dilated cardiomyopathy]. An Pediatr (Barc). 2016 Jul;85(1):51-2.

20. Koura HM, Abdalla NM, Hamed Ibrahim M, Abo Hashish MM, Zaki SM. NT-proBNP in Children With Left to Right Shunt and Dilated Cardiomyopathy. Iran J Pediatr. 2016 May 15;26(3):e4485.

21. Li X, Chen C, Gan F, Wang Y, Ding L, Hua W. Plasma NT pro-BNP, hs-CRP and big-ET levels at admission as prognostic markers of survival in hospitalized patients with dilated cardiomyopathy: A single-center cohort study. BMC Cardiovasc Disord. 2014 May 11;14:67.

22. Merlo M, Gigli M, Poli S, Stolfo D, Brun F, Lardieri G et al. Dilated cardiomyopathy: A dynamic disease - clinical course, reverse remodeling and prognostic stratification. G Ital Cardiol (Rome). 2016 Jan;17(1):15-23.

23. Hasham MG, Baxan N, Stuckey DJ, Branca J, Perkins B, Dent O et al. Systemic autoimmunity induced by the TLR7/8 agonist Resiquimod causes myocarditis and dilated cardiomyopathy in a new mouse model of autoimmune heart disease. Dis Model Mech. 2017 01;10(3):259-70.
24. Recla S, Schmidt D, Logeswaran T, Esmaeili A, Schranz D. Pediatric heart failure therapy: Why $\beta 1$-receptor blocker, tissue ACE-I and mineralocorticoid-receptor-blocker? Transl Pediatr. 2019 Apr; 8(2):127-32.

25. Hsu DT, Canter CE. Dilated cardiomyopathy and heart failure in children. Heart Fail Clin. 2010 Oct;6(4):415-32, vii.

26. Schranz D, Recla S, Malcic I, Kerst G, Mini N, Akintuerk H. Pulmonary artery banding in dilative cardiomyopathy of young children: Review and protocol based on the current knowledge. Transl Pediatr. 2019 Apr;8(2):151-60.

27. Mets G, Panzer J, De Wolf D, Bové T. An Alternative Strategy for Bridge-to-Transplant/Recovery in Small Children with Dilated Cardiomyopathy. Pediatr Cardiol. 2017 Jun;38(5):902-8.

28. Benke K, Sayour AA, Mátyás C, Ágg B, Németh BT, Oláh A et al. Heterotopic Abdominal Rat Heart Transplantation as a Model to Investigate Volume Dependency of Myocardial Remodeling. Transplantation. 2017 Mar;101(3):498-505.

29. Bertini M, Balla C, Pavasini R, Boriani G. Efficacy of cardiac resynchronization therapy in patients with isolated ventricular noncompaction with dilated cardiomyopathy: A systematic review of the literature. J Cardiovasc Med (Hagerstown). 2018 Jul;19(7):324-8.

30. Arı ME, Yoldaş T, Örün UA, Karademir S. Idiopathic dilated cardiomyopathy in children: Prognostic indicators. Turk Kardiyol Dern Ars. 2019 Apr;47(3):207-15. 